\title{
Multilevel lumbosacral fusions: Complications and patient-reported outcome
}

\author{
V Mandizvidza MBChB(UZ), FCS Ortho(COSECSA) \\ Spine fellow \\ RN Dunn MBChB(UCT), MMed(UCT), FCS(SA)Ortho \\ Pieter Moll and Nuffield Chair of Orthopaedic Surgery: University of Cape Town \\ Department of Orthopaedic Surgery, Groote Schuur Hospital, Cape Town, South Africa \\ Corresponding author: \\ Prof Robert Dunn \\ Department of Orthopaedic Surgery \\ H49 Old Main Building \\ Groote Schuur Hospital \\ Anzio Road \\ 7925 Observatory \\ Cape Town, South Africa \\ Email: prof@spinesurgery.co.za, info@spinesurgery.co.za
}

\begin{abstract}
The ageing population presents with debilitating back pain and leg pain with a background of adult spinal deformity, after a protracted period of conservative care. Sagittal balance is required to achieve a good clinical outcome; however, the surgery is associated with a high incidence of complications.

Aim: To review the outcome of multilevel $(\geq 4)$ instrumented lumbar fusion to sacrum/pelvis performed for degenerative conditions.

Methods: A retrospective descriptive study of 47 consecutive patients from 2002 to 2012. Inclusion criterion was fusion from at least L2 to S1 / pelvis, i.e. minimum of four levels. Imaging was assessed as to the restoration of normal sagittal profile as well as subsequent fusion. EQ5D, ODI and VAS scores pre-op and at 6 months post-op were analysed. Average age at surgery was 64 years (50-78). Thirteen cases were primary and 34 revisions. Indications were axial back pain either associated with sagittal imbalance $(40 \%)$ or leg pain (36\%) and leg pain alone in $10 \%$.

Results: The intra-operative blood loss averaged 2222 (250-7 000) ml with 40\% re-infusion from cell-saver. The average surgical duration was 268 minutes.

Proximal extent of instrumentation was T2 (1), T3 (1), T4 (2), T8 (1), T9 (1), T10 (17), T11 (2), T12 (5), L1 (4) and L2 (13). TLIFs were done in 20 cases mostly at the base of the construct. Pedicle subtraction osteotomies were performed in 14 revision cases. Dural tears occurred in 14 cases, all revision cases except one.

Wound infection occurred in three cases. With the exception of transient quadriceps weakness related to osteotomy, no neurological complications occurred. One patient died peri-operatively. Subsequent revision was required in 13 cases for instrumentation failure. The OSD score improved by 15.3 points on average, which is clinically and statistically significant.

Conclusion: Long lumbar fusions remain technically demanding with a high incidence of adverse events. This is due to the nature of revision surgery and high biomechanical demands on constructs. Surgical intervention can however be justified by the desperation of the cohort in terms of pain and poor function which can be modestly improved with this intervention.
\end{abstract}

Key words: adult deformity, sagittal imbalance, spine, complications 


\section{Introduction}

Adult spinal deformity may result in sagittal and/or coronal imbalance of the spine. Debilitating axial or radicular lower limb pain makes these desperate patients seek medical attention.

Most patients engage in a protracted period of conservative management before they present to the spinal surgeon. Surgical intervention is expensive and extensive and only a few of these patients end up undergoing surgery.

Adult spinal deformity surgery requires a special skill set and is associated with a high incidence of complications. ${ }^{2-4}$ The decision to abort conservative management for surgical intervention can be difficult. Recent evidence has shown that surgically treated patients do better than conservatively managed ones in terms of pain and healthrelated quality of life (HRQOL) outcomes. ${ }^{5,6}$

A balanced spine in the sagittal plane is important to achieve a good clinical outcome., ${ }^{78}$ This is achieved by recreating a lumbar lordosis that is appropriate for the patient's pelvic incidence and good surgical technique to avoid proximal junction failure.

The purpose of this study was to review the outcome of multilevel lumbar fusions (minimum of four levels).

\section{Materials and methods}

\section{Patient population}

Following institutional ethics approval, the senior author's prospectively maintained database was interrogated for adult patients who had undergone fusions to the sacrum of at least four levels, i.e. minimum of L2 to S1. Forty-seven patients were identified, with an average follow-up 46 months.

In addition to the demographics, operative and outcome tool data from the database, case notes and radiology were reviewed.

\section{Outcome measurements}

\section{Clinical outcome measurement}

All surgical patients are prospectively scored to assess health-related quality of life (HRQOL) at our unit. This is done pre-operatively on admission, and again at the 6-month post-operative mark.

The following scores were used:

- The Oswestry Disability Index (ODI). It assesses painrelated disability by asking ten questions on limitations in daily activities. It is specific to back pain. The score is reported as a percentage where a larger number is indicative of greater disability. ${ }^{9}$

- The Roland Morris disability index. This assesses if the back pain may make it difficult for them to do some of the things they normally do. They select from a list of 18 activities. Scored out of a total of 18,1 is given for a mark and 0 for no mark.

\section{Adult spinal deformity surgery requires a special skill set and is associated with a high incidence of complications}

- EQ5D. It is used to evaluate health-related quality of life by assessing the patient's mobility, self-care, usual activities, pain and anxiety. It also comprises a visual analogue score, the EQ Slider. This ranges from 0 (worst imaginable health state) to 100 (best imaginable health state).

- Visual Analogue Pain Scale (VAS). This assesses pain on a scale of 0 to 10 .

\section{Radiographic measurement}

All the images were obtained from the hospital's electronic database. Full-length scoliosis views were obtained for patients with clinical sagittal imbalance, and for those who were clinically well balanced, views were restricted to the thoracolumbar spine. Measurements were carried out using Surgimap software. These included lumbar lordosis (upper endplate of L1 vertebra to upper endplate of S1 vertebra), C7 plumb-line distances, and pelvic incidence.

\section{Statistical analysis}

A paired $t$-test was used to analyse the differences between the pre-operative and post-operative follow-up HRQOL scores. The level of significance was set at $\mathrm{P}<0.05$.

\section{Results}

Of the 47 patients identified all had adult degenerative deformity with two complicated with underlying Parkinson's.

The most common indication for surgery was debilitating axial low back pain (LBP), either associated with sagittal imbalance $(40 \%)$ or leg pain $(36 \%)$ (Table I). The three patients with paraparesis had supra-adjacent level stenosis and sagittal imbalance leading to bilateral leg weakness.

\begin{tabular}{|l|c|}
\hline \multicolumn{2}{|l|}{ Table I: Indications for surgery } \\
\hline Indication for surgery & $\begin{array}{c}\text { Number } \\
\text { of cases }\end{array}$ \\
\hline Sagittal imbalance \& LBP & $19(40 \%)$ \\
\hline LBP \& leg pain & $17(36 \%)$ \\
\hline Leg pain & 4 \\
\hline LBP & 4 \\
\hline Sagittal imbalance \& paraparesis & 3 \\
\hline
\end{tabular}


All the cases were instrumented to S1, with five cases extended to the pelvis. The most commonly instrumented levels were T10-S1 (36\%) followed by L2-S1 (28\%). Three cases were instrumented from the proximal thoracic spine (Table II).

\begin{tabular}{|l|c|}
\hline Table II: Levels of fusion \\
\hline Levels & $\begin{array}{c}\text { Number } \\
\text { of cases }\end{array}$ \\
\hline L1-S1 & 3 \\
\hline L2-S1 & $13(28 \%)$ \\
\hline T10-S1 & $17(36 \%)$ \\
\hline T11-S1 & 2 \\
\hline T12-S1 & 5 \\
\hline T8-S1 & 1 \\
\hline T9-S1 & 1 \\
\hline L1-PEL & 1 \\
\hline T4-PEL & 2 \\
\hline T3-PEL & 1 \\
\hline T2-PEL & 1 \\
\hline
\end{tabular}

Pedicle subtraction osteotomies (PSO) were performed in 15 cases, 14 of which were revision cases. Trans-foraminal lumbar inter-body fusions (TLIF) were performed at a single level in 17 cases and two in eight cases.

The average blood loss for all the cases was $2222 \mathrm{ml}$ (range 250-7000, SD 1 387). Isolating only the cases that had PSO performed the average blood loss was $3430 \mathrm{ml}$ (range $1800-7$ 000, SD 1438 ) compared to $1760 \mathrm{ml}$ (range 250-4 500, SD 1387 ) for the remaining cases. A cell saver was used for 26 cases; out of $2766 \mathrm{ml}$ collected an average of $1074 \mathrm{ml}(39 \%)$ was transfused. The average surgical time was 268 minutes (150-455, SD 70), and when we isolated cases that had PSO performed, the average surgical time was 326 minutes compared to the remaining cases with an average time of 246 minutes (range 150-455).

Complications encountered included 14 dural tears (30\%) and massive intra-operative haemorrhage. The $7000 \mathrm{ml}$ blood loss occurred in an L4 pedicle subtraction osteotomy through an existing fusion mass. The cell saver allowed $2100 \mathrm{ml}$ to be re-infused. One patient died two days post-operatively while in the intensive care unit and the postmortem performed did not establish the actual cause of death. Three cases had wound sepsis requiring washouts and intravenous antibiotic therapy to settle.
Transient quadriceps weakness was noted in patients who had pedicle subtraction osteotomies.

There were 13 subsequent revisions from our cohort; eight had pseudarthrosis leading to instrument failure (Table III). Three out of four episodes of rod fracture occurred at the level of the PSO (Figure 1).

A total of 30 patients had complete data on patientreported outcome scores. Poorer outcomes were noted in the personal care $(\mathrm{P}=0.18)$ and lifting $(\mathrm{P}=0.19)$ domains. The other categories of the Oswestry score had good outcomes (Table IV). The average overall change was 15.3, which is clinically significant as well as statistically significant $(\mathrm{P}=0.0001)$.

The Roland Morris disability index was on average 12.7 pre-operatively and nine post-operatively which was a good outcome $(\mathrm{P}=0.0003)$. The Visual Analogue Scale had statistically significant reduction on the patients' average pain ( $\mathrm{P}=0.00009)$, pain level at its best $(\mathrm{P}=0.005)$ and pain level at its worst $(\mathrm{P}=0.0005)$. There was no significant change in the pain now $(\mathrm{P}=0.08)$. There was no significant change in the EQ5D improved by 0.6 points $(\mathrm{P}=0.3)$, and EQ Slider improved by $5.24(\mathrm{P}=0.3)$.

The most common indication for surgery was debilitating axial low back pain (LBP), either associated with sagittal imbalance $(40 \%)$ or leg pain $(36 \%)$

\begin{tabular}{|c|c|c|}
\hline Revision & Months & Complication \\
\hline 1 & 15 & $\begin{array}{l}\text { Pseudoarthrosis L3-S1 and } \\
\text { broken rods }\end{array}$ \\
\hline 2 & 9 & $\begin{array}{l}\text { Pseudoarthrosis L5/S1 and } \\
\text { loose S1 screws }\end{array}$ \\
\hline 3 & 9 & $\begin{array}{l}\text { Pseudoarthrosis L2-4 and } \\
\text { broken rods }\end{array}$ \\
\hline 4 & 7 & Positive sagittal balance \\
\hline 5 & 3 & Loose S1 screws \\
\hline 6 & 54 & Positive sagittal imbalance \\
\hline 7 & 12 & $\begin{array}{l}\text { Pseudoarthrosis L2/3 and } \\
\text { broken rods }\end{array}$ \\
\hline 8 & 45 & $\begin{array}{l}\text { Pseudoarthrosis L5/S1 and } \\
\text { loose S1 screws }\end{array}$ \\
\hline 9 & 1 & Loose L1 screws \\
\hline 10 & 40 & $\begin{array}{l}\text { Pseudoarthrosis L5/S1 and } \\
\text { broken rods }\end{array}$ \\
\hline 11 & 28 & Pseudoarthrosis L5/S1 \\
\hline 12 & 10 & $\begin{array}{l}\text { Pseudoarthrosis L3/4 and } \\
\text { loose rods }\end{array}$ \\
\hline 13 & 5 & Stenosis L1-3 \\
\hline
\end{tabular}




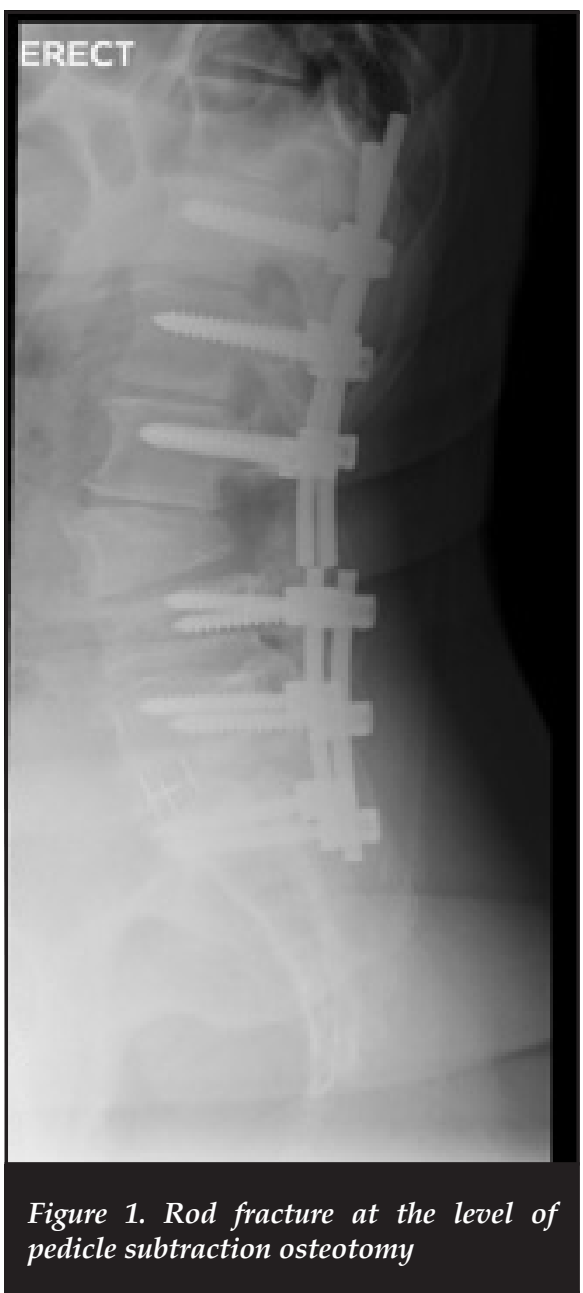

Table IV: Oswestry Disability Index, average scores and corresponding $P$ values

\begin{tabular}{|l|r|r|l|}
\hline \multicolumn{1}{|c}{} & \multicolumn{1}{c}{$\begin{array}{c}\text { Pre-op } \\
\text { score }\end{array}$} & \multicolumn{1}{c}{$\begin{array}{c}\text { Post-op } \\
\text { score }\end{array}$} & \multicolumn{1}{l|}{ P-value } \\
\hline Pain intensity & 2.3 & 1.8 & 0.03 \\
\hline Personal care & 1.7 & 1.3 & 0.18 \\
\hline Lifting & 3.4 & 3.2 & 0.19 \\
\hline Walking & 2.6 & 1.8 & 0.004 \\
\hline Sitting & 2.3 & 1.4 & 0.0006 \\
\hline Standing & 3.3 & 2 & 0.000005 \\
\hline Sleeping & 1.6 & 0.9 & 0.003 \\
\hline Social life & 2.9 & 1.4 & 0.0003 \\
\hline Travelling & 1.9 & 1.4 & 0.01 \\
\hline Employment & 2.8 & 1.8 & 0.0007 \\
\hline TOTAL & 49.2 & 33.9 & $\mathbf{0 . 0 0 0 1}$ \\
\hline
\end{tabular}

Table V: Number of cases within different ranges of pelvic incidence (PI) - lumbar lordosis (LL)

\begin{tabular}{|l|c|}
\hline PI -LL & $\begin{array}{c}\text { Number } \\
\text { of cases }\end{array}$ \\
\hline$\leq 10$ & 19 \\
\hline $11^{\circ}-20^{\circ}$ & 10 \\
\hline $21^{\circ}-40^{\circ}$ & 11 \\
\hline$>40^{\circ}$ & 1 \\
\hline
\end{tabular}

A total of 41 patients had complete radiological data to allow measurement of lumbar lordosis and pelvic incidence. The average pre-operative lumbar lordosis was $32^{\circ}$ (range $1-73, \mathrm{SD} \pm 18.0$ ), and average post-operative was $45^{\circ}$ (range $1-70, S D \pm 14.9$ ). The average pelvic incidence was $61^{\circ}$ (range $41-83, S D \pm 11$ ). We had 19 patients with lumbar lordosis within $10^{\circ}$ of their pelvic incidence and 10 patients were in the range $11^{\circ}-20^{\circ}$ of their pelvic incidence (Table $V$ ).

The case illustrated in Figure 2, is an example from this series, illustrating the sagittal profile pre-operatively and post-operatively.

\section{Discussion}

This type of surgery is associated with a high rate of complications. The major complications we noted in our study were dural tears, intra-operative haemorrhage, wound sepsis and pseudarthrosis leading to instrumentation failure. Schairer et $a .^{10}$ reported risk factors leading to complications requiring readmission were longer fusion length, higher patient severity of illness and specific medical comorbidities. Surgical site infection accounted for $45.6 \%$ of their $8.4 \%$ rate of readmission. Our study's rate of wound sepsis was $6.3 \%$ (three out of 47 cases).

Of the 13 patients that required revision subsequent to our procedure, the majority were due to instrumentation failure $(84.6 \%)$ mostly with underlying pseudarthrosis (Figure 3). This is similar to a report by Scheer et al. ${ }^{11}$ Despite the high risk of complications, surgically treated patients improve on their pre-operative morbidity. Patients present with disabling back pain, leg pain and poor health status baseline. They improve significantly with operative versus nonoperative treatment. ${ }^{5,6}$ The first line of treatment in adult degenerative scoliosis still remains non-operative. Surgery is offered when conservative care fails in a patient who understands the complexity of the procedure and is willing to take the risks of surgery and failure.

Despite the high risk of complications, surgically treated patients improve on their pre-operative morbidity 


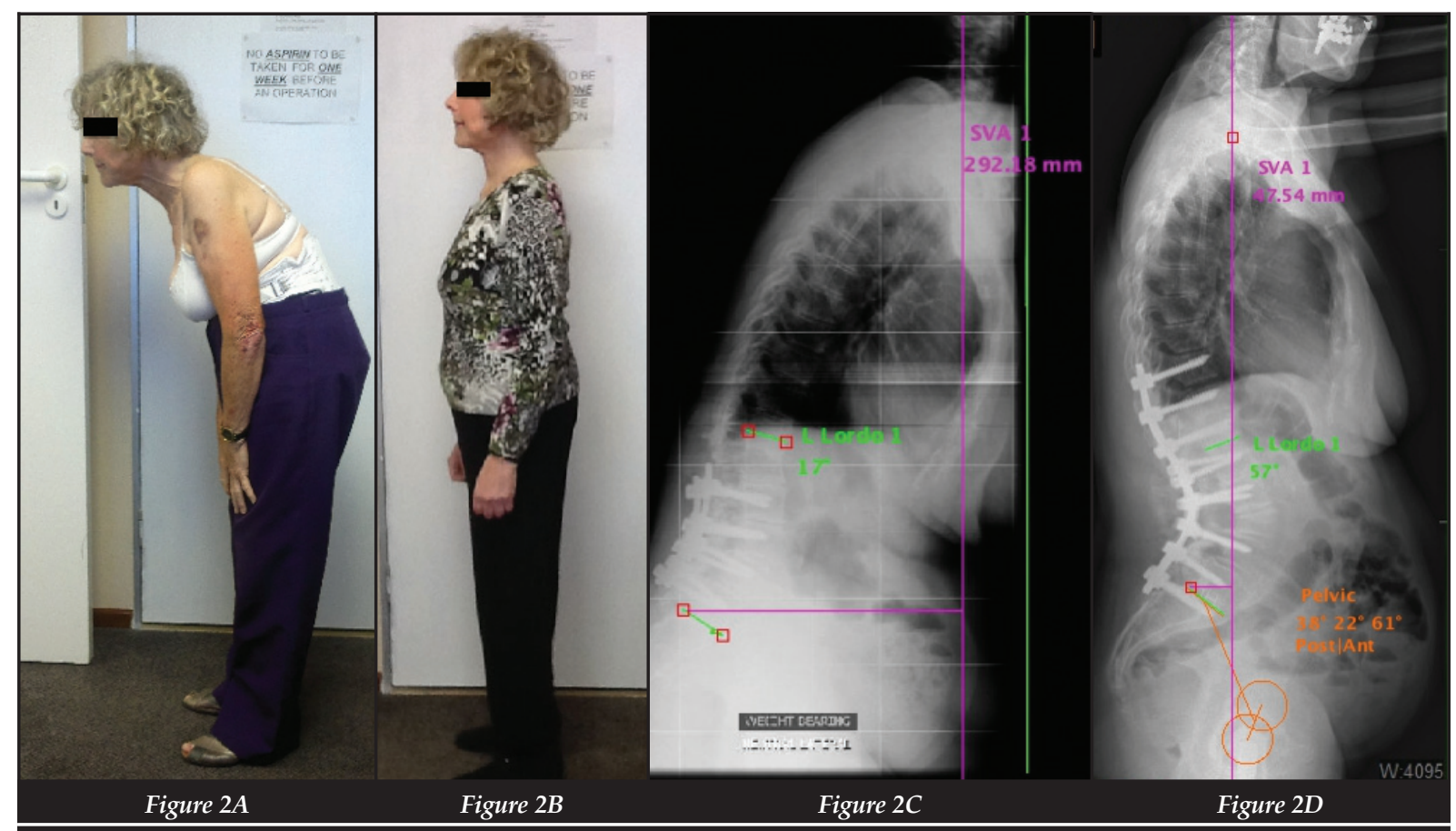

Figure 2. A representative case from the series. A 76-year-old woman presented listing forward (A), with back pain. Radiographs revealed an SVA $292.18 \mathrm{~mm}$ and Lumbar lordosis $17^{\circ}(\mathrm{C})$. Post-operatively she was corrected to an upright posture (B), SVA $47.54 \mathrm{~mm}$, lumbar lordosis $57^{\circ}$ with a pelvic incidence $61^{\circ}(D)$. Procedures done were T10-S1 fusion, L3 PSO, L5/S1 TLIF.

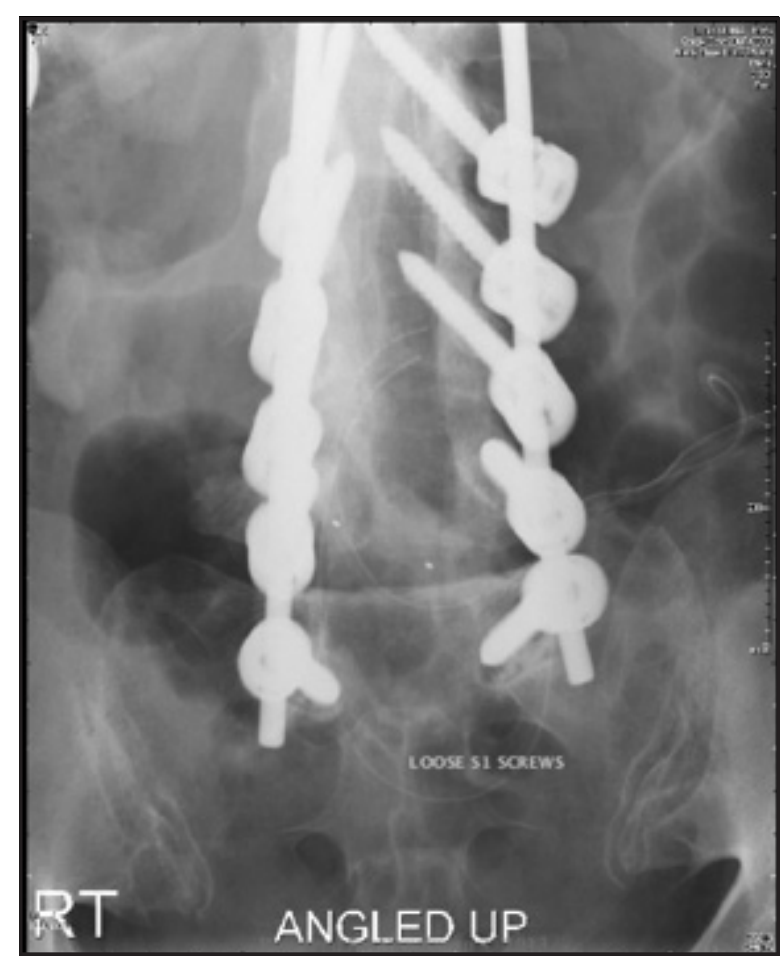

Figure 3. L5/S1 pseudoarthrosis with loose S1 screws
Despite the high complication rates we had a statistically significant improvement in the ODI. The overall change was 15.3 points, which is clinically significant as it is above the minimum clinically detectable change. When reviewing the domains making up the ODI, pain intensity, walking, sitting, standing, sleeping, social life, travelling and homemaking improved significantly. Personal care and lifting did not change significantly. This is to be expected since the fusion results in reduced range of motion, making it difficult for patients to execute activities requiring lower back mobility. Our patients are warned about this prior to surgery.

Glassman et al. ${ }^{8}$ suggest that restoration of normal sagittal balance is the critical goal of reconstructive spine surgery. Nineteen of our patients' lumbar lordosis was within $10^{\circ}$ of the pelvic incidence and ten were near normal. The rest were inadvertently under-corrected, attributed to the surgeon's learning curve over the years. We currently strive to achieve Glassman's recommendation which has resulted in more aggressive surgical techniques such as PSOs in the latter part of the study. This however comes at the price of increased cost and risk.

When reviewing the domains making up the ODI, pain intensity, walking, sitting, standing, sleeping, social life, travelling and homemaking improved significantly 


\section{Conclusion}

Long lumbar fusions remain technically demanding with a high incidence of adverse events. This is due to the nature of revision surgery and high biomechanical demands on the constructs.

Surgical intervention can however be justified by the desperation of the cohort in terms of pain and poor function which can be improved.

The University of Cape Town, Faculty of Health Sciences Human Research Ethics Committee approved this study. Reference number HREC REF:012/2014.

The authors have no funding sources to declare. No conflicts of interest exist.

\section{References}

1. Bess S, Boachie-Adjei O, Burton D, et al. Pain and disability determine treatment modality for older patients with adult scoliosis, while deformity guides treatment for younger patients. Spine 2009;34:2186-90.

2. Daubs MD, Lenke LG, Cheh G, et al. Adult spinal deformity surgery: complications and outcomes in patients over age 60. Spine 2007;32:2238-44.

3. Carreon LY, Puno RM, Dimar JR 2nd, et al. Perioperative complications of posterior lumbar decompression and arthrodesis in older adults. J Bone Joint Surg Am 2003;85A:2089-92.

4. Schairrer WW, Carrer A, Deviren V, et al. Hospital readmission after spine fusion for adult spinal deformity. Spine 2013;38:1681-89.
5. Smith JS, Shaffrey CI, Berven S, et al. Operative versus nonoperative treatment of leg pain in adults with scoliosis: a retrospective review of a prospective multicenter database with two-year follow-up. Spine 2009;34:1693-98.

6. Smith JS, Shaffrey CI, Berven S, et al. Improvement of back pain with operative and nonoperative treatment in adults with scoliosis. Neurosurgery 2009;65:86-93.

7. Glassman SD, Bridewell K, Dimar JR, et al. The impact of positive sagittal balance in Adult spinal deformity. Spine 2005;30:2024-29.

8. Glassman SD, Berven S, Bridewell $\mathrm{K}$, et al. Correlation of radiographic parameters and clinical symptoms in adult scoliosis. Spine 2005;30:682-88.

9. Fairbank JC, Pynsent PB. The Oswestry Disability Index. Spine 2000;25:2940-52.

10. Schairer WW, Carrer A, Deviren V, et al. Hospital readmission after spine fusion for adult spinal deformity. Spine 2013;38:1681-89.

11. Scheer JK, Tang JA, Smith JS, et al. Reoperation rates and impact on outcome in a large, prospective, multicenter, adult spinal deformity database. I Neurosurg Spine 2013;19(4):464-70.

This article is also available online on the SAOA website (www.saoa.org.za) and the SciELO website (www.scielo.org.za). Follow the directions on the Contents page of this journal to access it. 